\title{
Absence of Ketamine Effects on Learning \& Memory Following Exposure during Early Adolescence: A Preliminary Report
}

\author{
Shannon 0’Brien, David Compton* ${ }^{\circledR}$, Julianna M. Davis, Jennifer Elvir, Adrien Albritton \\ Department of Psychology, Behavioral Neuroscience Program, Palm Beach Atlantic University, West Palm Beach, USA \\ Email: ^david_compton@pba.edu
}

How to cite this paper: O'Brien, S., Compton, D., Davis, J.M., Elvir, J. and Albritton, A. (2021) Absence of Ketamine Effects on Learning \& Memory Following Exposure during Early Adolescence: A Preliminary Report. Journal of Behavioral and Brain Science, 11, 27-47.

https://doi.org/10.4236/jbbs.2021.111003

Received: November 22, 2020

Accepted: January 16, 2021

Published: January 19, 2021

Copyright $\odot 2021$ by author(s) and Scientific Research Publishing Inc. This work is licensed under the Creative Commons Attribution International License (CC BY 4.0).

http://creativecommons.org/licenses/by/4.0/

(c) (i) Open Access

\begin{abstract}
Traditionally, ketamine was considered useful as a dissociative anesthetic. More recently, ketamine has been examined for its effects as a fast-acting antidepressant, for treatment-resistant depression, and as a non-opiate treatment of chronic pain. Unfortunately, ketamine has enjoyed popularity as a recreational drug among both adolescents and young adults. While some research suggests the use of this drug during neurodevelopment is not without consequence, relatively little work has been conducted to examine the chronic effects of ketamine on the adolescent brain at different stages of neural development. Using a rodent model of development, we probed the effects of early adolescent exposure to ketamine. Between postnatal days 22 to 40 , a period comprising early to mid-adolescence, rats were exposed to one of two doses of ketamine or saline. Beginning at 90 days of age and drug free for 50 days, a series of neuropsychological assessments were employed to examine general activity, spatial navigation, as well as nonspatial response learning. Contrary to prediction, except for differences in general activity levels, no spatial or nonspatial impairments were found among the drug- and saline-treated animals. The present results are considered in light of ketamine-associated effects found in a related study with older adolescent rats and the role of drug exposure during different points in adolescent brain development.
\end{abstract}

\section{Keywords}

Ketamine, Neuropsychological Assessment, Learning, Memory, Rat

\section{Introduction}

Originally developed and approved for use in the early 1960s, the drug ketamine 
[( \pm )-2-(2-chlorophenyl)-2-(methylamino)-cyclohexanone)], has remained popular as a veterinary anesthetic with dissociative properties. Ketamine (KET) has proven efficacy in disrupting pain awareness without the accompanying side effects associated with depression of autonomic reflexes associated with opiates [1]. Further, the drug has a number of desirable qualities such as rapid onset effects when an IV injection is required, and an elimination half-life of from two to three hours [2] [3].

In recent years, KET has been administered off-label for MDD (major depressive disorder) and chronic pain conditions subsequent to first-line medication ineffectiveness or conventional treatment failure [4] [5] [6] [7] [8], with its S-isomer esketamine developed as an intranasal spray for TRD (treatment-resistant depression) [9]. When used as a dissociative anesthetic, the effects of KET involve a number of well-described out-of-body experiences, that include an individual observing one's own body and the experience of pain as a third-party observer [10]. While the exact mechanism of action of KET for its antidepressant effects is still being elucidated, research suggests the antidepressant effects may be independent of its antagonistic NMDAR action [11].

More important, because of its effects, KET has become recognized as a recreational drug of abuse among not only adults, but among preadolescent and adolescent individuals as well [12]. Recreational use of KET began in the United States, spreading to other countries usually as part of the "rave" culture [13] [14] [15]. With street names such as special $\mathrm{K}$, jet, cat valium, vitamin $\mathrm{K}, \mathrm{K}-$ hole, Kit Kat, and liquid E, KET use became more prominent in the 1980 and 1990s not only as a "club drug" and also due to use in drug-facilitated sexual assault [2].

While past research suggests considerable variability in the patterns of use (e.g., [16] [17]), the prevalence may be largely underreported [18]. This may be especially true for teens and young adults which attend dance parties or raves, where the use of drugs such as LSD, Ecstasy, (MDMA), and KET, alone or in various combinations is common [19] [20]. Given the recent spike in media coverage regarding KET, there may well be an increase in deliberate consumption for recreational purposes as well as possible inadvertent exposure through use of adulterated drugs [18].

Given that KET acts as a noncompetitive antagonist at NMDA receptors, found throughout the cerebral cortex and the hippocampus, and these receptors likely play a role in long-term potentiation, effects on memory could be predicted. In fact, these predictions were supported by the evidence [21]. According to the Lofwall and colleagues, KET appears to produce a selective impairment to encoding and working memory. However, there appears to be little in the way of a KET associated deficit on memory recall or attention [21]. This has been demonstrated in other studies where episodic and working memory impairments were dose-dependent [22] [23]. In addition, larger doses of KET produce a reduction in the speed of semantic processing, impairing recognition memory and procedural learning, while largely sparing perceptual priming and executive functioning [22]. 
There have also been reports that KET can cause semantic memory impairments up to three days after ingestion for recreational use [23] [24]. While in use, KET seems to cause dissociative effects and impairment of working, episodic, and semantic memory similar to the impairments associated with schizophrenia [23] [25]. Further, under the influence of KET, individuals also display problems with spatial working memory and reduced activity in the lateral prefrontal cortex when compared to individuals not dosed with KET [26]. Last, long-term KET use has been linked a number of depressive, dissociative, and delusional thought processes [27] [28] [29].

In the rodent model of development, adolescence is normally delineated as the period from the 21st postnatal day (PND) until PND 60. As developmental periods, mid-adolescence encompasses PNDs 34 to 46, including PNDS 46 to 59 [30]. In addition, PNDs 34 to 46 and 46 to 59 are considered analogous to periadolescence and late adolescence/early adulthood, respectively [30]. As a model of rodent development, this framework has proven useful for comparative evaluation and extrapolation to humans [31].

As a period of development, adolescence is marked by a number of alterations in the brain [32]. While there is variation across species, mammalian neurodevelopmental changes across adolescence follow a similar pattern [33]. For example, the period is noted as one of continued maturation of myelination, substantial synaptic pruning, and a concomitant decrease in both cortical and subcortical gray volume [34] [35]. Further, there is considerable evidence that drug exposure during adolescence is associated with consequences that differ from those often seen with exposure in adulthood. As such, such drug exposure has the potential to have a profound impact on the neural, cognitive, and behavioral level that persists long after the exposure period [32] [36]. Thus, exposure to substances that have the potential to alter permanently key neuropsychological processes - many of which are highly addictive-is of considerable import.

Past research in our lab examined the effects of KET exposure in adolescent animals at ages that generally included late adolescence, including the boundary of early adulthood. Depending on the demands of the task, the results suggested a variety of cognitive deficits that varied in severity [37] [38]. Here, we considered repeated KET exposure in younger adolescent rats on cognition in adulthood, long after the period of drug exposure. Adolescents are not only more susceptible to substance abuse but are also at risk of mental illness [39]. Since KET may provide an effective way to treat mental illness, it is important to understand what effects KET may have on adolescent individuals. Thus, in the present study, the long-term effects on spatial and nonspatial memory caused by KET exposure during early to mid-adolescence were examined.

\section{Method}

\subsection{Subjects}

The subjects were 22-day-old male $(n=21)$ Sprague-Dawley rats, purchased 
from Charles River, (Wilmington, MA). The rats were housed in standard ( $~ 864$ sq $\mathrm{cm}$ ) polycarbonate cages in a climate-controlled facility. Housing was maintained on a 12-hour light/dark cycle, with food (Mazuri Rodent Chow) and water provided ad libitum. The rats were maintained in a manner consistent with the appropriate care of laboratory rodents, under a research protocol approved by the Institutional Animal Care and Use Committee of Palm Beach Atlantic University.

An overview of rat developmental periods and the experimental plan is presented in Figure 1. Before the experiment began, the rats were randomly assigned to one of three-drug treatment conditions: KET $40 \mathrm{mg} / \mathrm{kg}(n=7), \mathrm{KET} 10$ $\mathrm{mg} / \mathrm{kg}(n=7)$, or a saline control group $(n=7)$. Drug exposure began when the rats were in the mid-adolescent period of development (i.e., 39 days old). All rats received a total of 10 injections of either $10 \mathrm{mg} / \mathrm{kg}$ or $40 \mathrm{mg} / \mathrm{kg}$ of Ketamine HCL (Henry Schein, Melville, NY) or a corresponding volume of isotonic saline. Injections were delivered IP at a volume of $2.5 \mathrm{ml} / \mathrm{kg}$. During the period of all drug exposure sessions, the ambient temperature was maintained at approximately $24^{\circ} \mathrm{C}$ with the humidity between $50 \%$ and 56\%. Drug exposure occurred during PNDs 22 to 40, a period largely comprising early into mid-adolescence [30]. Behavioral testing occurred in adulthood when the rats were 90 days old and had been drug free for 50 days.

Before the beginning of the data collection, one saline rat died due to the stress of transportation. Prior to the start of the study, each rat was randomly assigned to one of three-drug treatment conditions: KET $40 \mathrm{mg} / \mathrm{kg}(n=7), \mathrm{KET} 10$ $\mathrm{mg} / \mathrm{kg}(n=7)$, or a saline control group $(n=6)$. Drug exposure began when the rats reached the mid-adolescent period of development (43 days old). All rats received a total of 10 injections of either $10 \mathrm{mg} / \mathrm{kg}$ or $40 \mathrm{mg} / \mathrm{kg}$ of Ketamine HCL (100 mg/ml; Henry Schein, Melville, NY) or a corresponding volume of isotonic

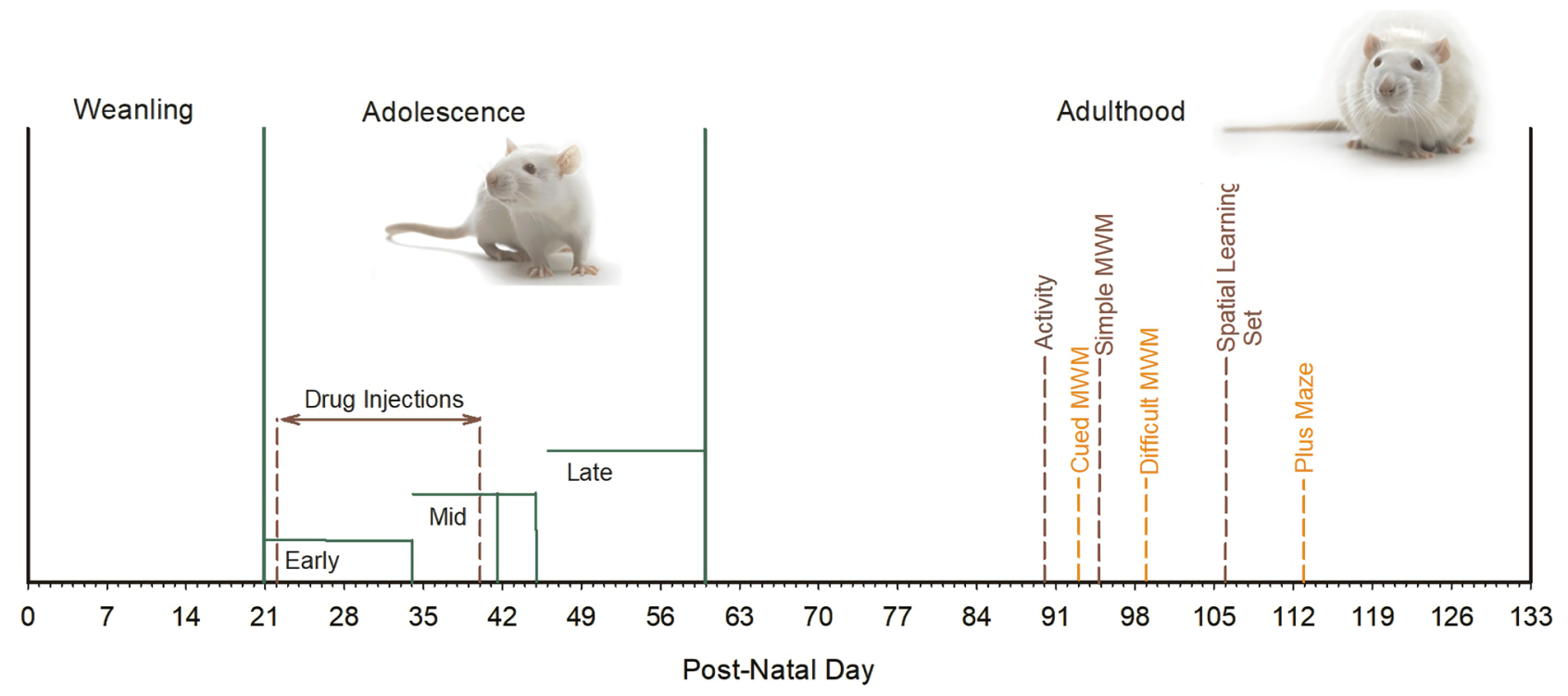

Figure 1. A timeline of the main steps of the study. See Tirelli et al. [30] for additional information on rat adolescence. 
saline. Intraperitoneal injections were delivered at a volume of $1 \mathrm{ml} / \mathrm{kg}$. During all drug exposure sessions, the ambient temperature was maintained at approximately $24^{\circ} \mathrm{C}$ with the humidity between $45 \%$ and $50 \%$. Drug exposure occurred during postnatal days 43 to 57 . Behavioral testing occurred once the rats reached adulthood and had been drug free for approximately 42 days. A timeline of phases of the experiment can be seen in Figure 1.

\subsection{Apparatuses}

\subsubsection{General Activity}

The general level of activity in the rats was evaluated across two five-minute sessions (one per day) in an open-field chamber $60.96 \mathrm{~cm} \times 60.96 \mathrm{~cm}$ chamber consisting of $10.16 \mathrm{~cm}$ squares.

\subsubsection{Morris Water Maze (MWM)}

With the exceptions of general activity and the last phase of the experiment (see below, WRAM), the assessment of spatial learning and memory included the use of a standard Morris Water Maze. The maze was a circular white acrylic plastic swimming pool with a diameter of $183 \mathrm{~cm}$. Different extra-maze cues and escape parameters were used as a function of current task demands. The depth of the water was held constant at $30 \mathrm{~cm}$ and made opaque white using a nontoxic water-based paint (Sargant Art, Hazelton, PA). The swimming pool was located in a quiet testing space approximately 36.88 square meters in size. On two sides, a white curtain panel served as a barrier from the larger space while the remaining two walls consisted of a neutral white color with a computer, monitor, and other stimuli present and approximately two meters beyond the pool. This limited the external stimuli available to aid navigation when viewed from the surface of the pool. Except for free swim "probe" trials, a $15 \mathrm{~cm} \times 15 \mathrm{~cm}$ flat white escape platform was used throughout all the assessment phases of the MWM. For the cued water maze task described below, the escape platform projected $15 \mathrm{~mm}$ above the surface of the water. For the remaining phases of the MWM assessments, the escape platform was submerged to a depth of $15 \mathrm{~mm}$ below the surface of the water. Last, the platform was always located at a distance of $18 \mathrm{~cm}$ from the wall of the swimming pool.

\subsubsection{Water Radial Arm Maze (WRAM)}

A water-motivated escape version of the standard eight-arm radial maze was used for one phase of the experiment. Composed of white plastic $60.96 \mathrm{~cm}$ in height, the maze consists of eight equally spaced $14 \mathrm{~cm} \times 39.37 \mathrm{~cm}$ arms. All arms could be partitioned off as needed from an octagonal $15.5 \mathrm{~cm}$ central chamber. The water was made opaque using the same white non-toxic tempera paint described earlier. A white removable escape platform $9 \mathrm{~cm}$ (square) was used and submerged just below the water surface at a depth of approximately 15 $\mathrm{mm}$. With the WRAM task employed here-a nonspatial response learning task-four arms were blocked by Plexiglas barriers leaving open alleys in the standard plus configuration. Finally, a variety of extra-maze cues were available 
on two of the four walls of the testing room.

\subsection{Procedure}

\subsubsection{Assessment of General Activity}

The general level of activity in the rats was evaluated in five-minute sessions across two consecutive days in a $60.96 \mathrm{~cm} \times 60.96 \mathrm{~cm}$ checkerboard chamber consisting of $10.16 \mathrm{~cm}$ squares. Each session was recorded and scored by teams of two raters. The dependent measures of activity included the number of squares crossed and the number of times the rats rose onto their hind legs during the five-minute session. Last, consideration of sensorimotor and motivational deficits, if any, were examined using a cued version of the MWM task described in the following section.

\subsubsection{Morris Water Maze Tasks}

The series of water maze tasks used as part of the present protocol were chosen in order to provide a neuropsychological assessment of rodent learning and memory performance following KET exposure without the necessity of food deprivation required for traditional appetitive tests of memory. For the first phase of MWM testing-cued memory phase-the escape platform was visible, projecting $15 \mathrm{~mm}$ above the water's surface. For the remaining place and spatial learning set phases in the MWM, the escape platform was submerged $15 \mathrm{~mm}$ below the surface of the water. The spatial assessment phases of the experiment involved gently placing the rat into the pool at one of four cardinal compass points, with a designated ceiling of 60 seconds per trial to locate the escape platform. The location of the escape platform varied among one of four compass positions-southeast, southwest, northeast, northwest. If the rat did not locate the escape platform within 60 seconds, it was gently placed on the platform and permitted to rest for 15 seconds. Escape latencies were recorded with a stopwatch and quadrant crossings, operationally defined as crossing one of four quadrants associated with the four cardinal compass points, were tabulated by teams of no fewer than two experimenters.

\section{1) Simple (Cued) Place Learning}

The cued place learning MWM navigation task was administered after the drug recovery period and following the assessment of general activity and exploration. Given the potential for a number of sensorimotor and/or motivational changes [40], the cued place learning phase was included to determine whether such nonassociative influences developed, especially those that could potentially influence performance on the subsequent place learning, learning set, and WRAM response learning tasks. Therefore, in this phase of testing, the cued place learning phase included the use of a visible platform in order to assess general swimming capability, compromised motivation, and nondeclarative memory ability that could influence performance on other phases of the experiment. The rats received 10 trials per day for two days of testing. On each trial, the escape platform was located in one of four possible locations. After success- 
fully locating the platform, the rats were allowed to rest on the platform for about 15 seconds at the completion of each trial.

\section{2) Spatial Water Maze Tasks}

The next two phases following the cued place learning assessment, involved an examination of spatial reference memory in the MWM. Each phase is considered a test of spatial reference memory. However, the latter of these two is considered more challenging, because quite often only minor deficits are found using the standard version of this test [40] [41]. Since the more complex version has been shown to be sensitive for detecting spatial learning/memory impairments following adolescent drug exposure to other drugs such as MDMA or Foxy [41], it was considered prudent to include this phase in the present study.

With a number of extra-maze cues and a well-lit environment, the simple version of the place-learning task involved testing the rats for 10 trials a day for two days. Between each trial, the rats were allowed to remain on the platform for 15 seconds. In addition, a probe trial with the escape platform removed was used as a test of retention on the second day of this phase. The probe, followed no less than two hours after the last place learning trial, included testing the subject for a 60 second "free swim". Both the time spent swimming in the target quadrant and the number of crossings over the former platform location were recorded.

Difficult place learning testing was the next phase in the experiment. Here, the conditions were altered in order to provide a marked reduction in the availability of cues to aid navigation. Specifically, the room was indirectly lit by a single 60-watt red light bulb located beyond the curtain and below the horizon of the pool, at approximately three meters from the water maze. As in previous phases, a curtain was placed around the water maze. As a result, few visual cues remained to aid navigation. For this phase of place learning, the rats were trained four consecutive trials per day for five consecutive days. As in previous MWM phases, the rats were allowed to remain on the platform for 15 seconds after the completion of a trial. Daily probe trials were administered no less than two hours after the last trial of the preceding four trials. Spatial learning set acquisition, where successful escape included the daily requirement that the rat learn a different escape platform location, was the final MWM assessment phase. In this phase, efficient escape latencies on trial 2 required that the rat recall its prior trial 1 response including the new location of the platform. All the animals received four consecutive trials per day, with testing continuing for five consecutive days. Used as an index of working (short-term) memory, daily Trial 1 and Trial 2 escape latencies and response accuracy were compared. The rats were allowed to rest on the platform for 15 seconds at the completion of each trial.

\subsubsection{Water Radial Arm Maze Task}

The final phase included the WRAM and involved the use of a plus maze response-learning task. In this task, successful escape required that the rat learn to choose from three possible response alternatives-to turn right, to turn left, or to swim straight ahead. However, the escape platform was always located in an arm 
that required either a right or left turn. Using a Fellows [42] series, we chose two possible starting points. Consistent with all earlier tests, assessment in this phase began by gently lowering the animal to the surface of the water facing the rear wall of the start arm. As a result, in order to escape, the rat was required to turn $180^{\circ}$ and swim towards the three choices located at the center of the plus maze.

Here, the configuration of the task requirements was designed to assess both nonspatial response learning as well as perseverative behavior. Thus, within a given set of trials the animal began at one of two possible starting points and the configuration of the available allocentric information differed as a function of a given trial. Successful mastery of the task (i.e., learning to "turn right vs. left") required that the rat learn a rule to turn in a specific direction regardless of the specific starting location [43]. The goal remained fixed for each animal until a criterion of 9 out of 10 correct, where after the platform location was reversed. We have found that the ability to adjust flexible behavior as a function of available allocentric cues has proven to be useful in detecting perseverative behavior.

\subsection{Data Analyses}

For all MWM tasks and the plus maze response learning task escape latencies and navigation errors or response accuracy were the primary measures of performance. For the WRAM plus maze phase of the experiment, total errors were divided into working and reference memory errors. Last, the number of trials to first reversal was also assessed (see below, nonspatial response learning section).

When exploring the data associated with MWM tasks, depending on the start and escape loci, the optimal swim path distances differed considerably. Therefore, the recorded escape latencies for the start and goal locations were normalized. Normalization involved computation of the ratio of the minimum swim distance in $\mathrm{cm}$ for each of the longer swim paths to the escape platform to the minimum swim of the two shorter swim paths trials in $\mathrm{cm}$ [44].

All data analyses were performed using SPSS [45]. Generally, the statistical analyses involved mixed analysis of variance (ANOVAs), with drug groups as the between-subjects factor and days, or blocks of trials and days as within-subjects factors. For WRAM plus maze analysis, multivariate analysis of variance with drug group as the factor. Post-hoc analyses were performed using paired $t$-tests with a Bonferroni correction or Tukey $_{\mathrm{HSD}}$ as appropriate to control for multiple comparisons. The alpha level for acceptance was set at $p<0.05$.

\section{Results}

\subsection{General Activity}

In the first set of analyses, we examined the general exploratory activity of the animals by assessing the number of rearings and squares traversed across the two days of the assessment period. The relevant results are presented in Figure 2. Although the number of squares reversed did not differ by groups or days, a significant group $\mathrm{X}$ days interaction was detected, $F(2,18)=6.60, p=0.007, \eta_{p}^{2}$ 


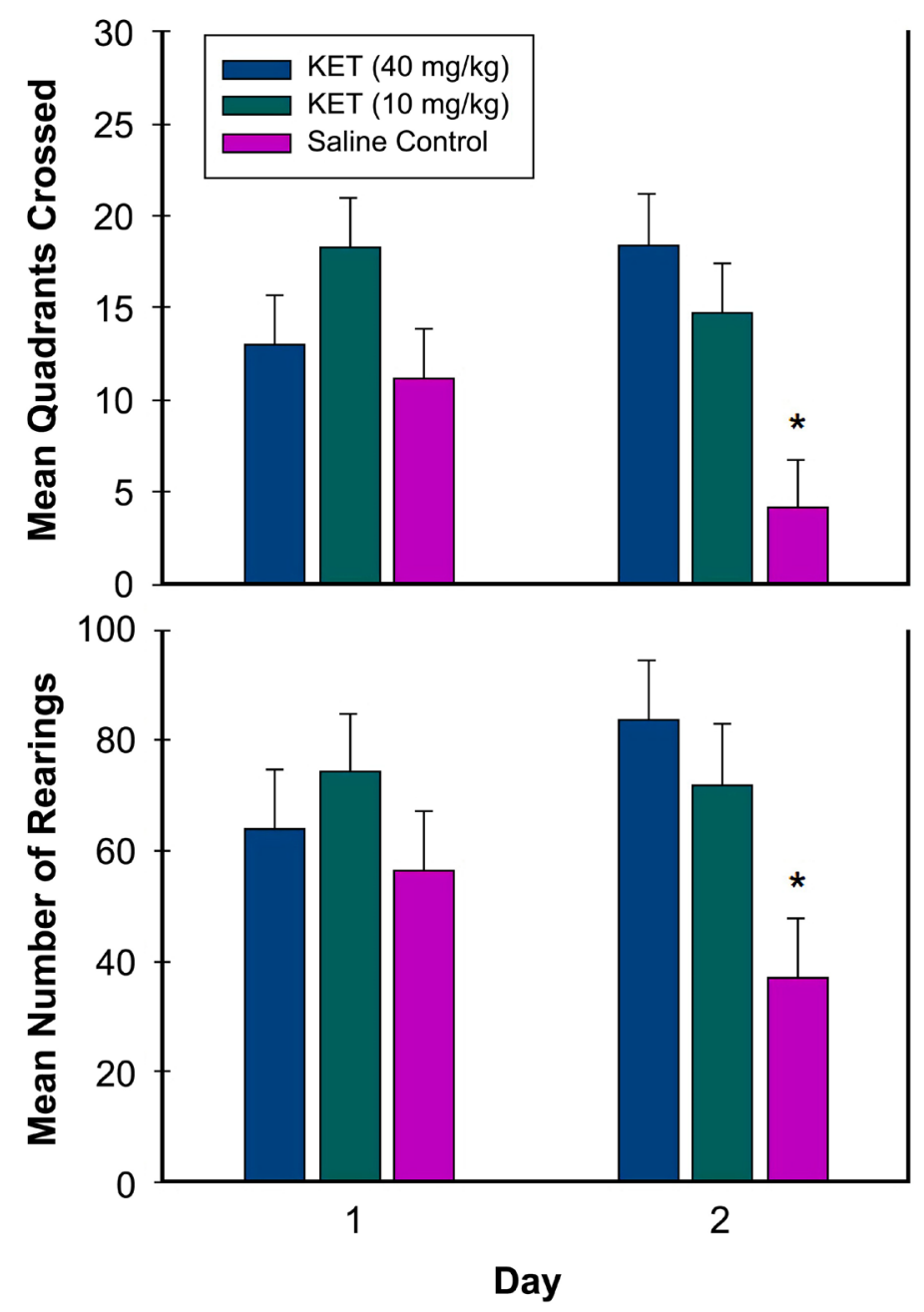

Figure 2. Mean quadrants crossed and number of rearings across the two days of the assessment of general activity. ${ }^{\star}$ Significantly different, $p<0.05$.

$=0.423$. Multiple comparisons of the group means with Tukey ${ }_{\mathrm{HSD}}$ by each day revealed similar levels of activity on the first day. However, on the second test day, both KET groups traversed significantly more squares than the saline control animals. The activity of the two KET drug groups was comparable. Similar results were obtained when the number of rearings was considered. Here, the main effect of group was significant, $F(2,18)=4.62, p=0.024, \eta_{p}^{2}=0.339$, as was the group $\mathrm{X}$ days interaction, $F(2,18)=4.88, p=0.020, \eta_{p}^{2}=0.352$. Once again, no differences were observed on the first assessment day but on day two, a significantly higher number of rearings was detected in the two-drug groups than animals in the control group. As before the two drug groups did not differ.

\subsection{Morris Water Maze Assessments}

\subsubsection{Cued Place Learning}

The first phase of MWM testing involved a cued place learning test. The data were collapsed into two blocks of five trials each and assessed for the two days of testing. Using a mixed (1-between (drug), 2-within (days, blocks of trials) ANOVA, 
both escape latencies and the number of quadrants crossed were considered. Examination of the escape latencies revealed no differences as a function of drug group. While the main effect of days was nonsignificant, the main effect of blocks $F(1,18)=16.63, p=0.001, \eta_{p}^{2}=0.480$, was, suggesting that escape latencies decreased within but not between sessions. All possible interactions were nonsignificant.

\subsubsection{Simple Place Learning}

Consideration of escape latency data from the simple (i.e., high available cues) place-learning phase revealed similar outcomes. Analysis of the escape latency data with 1-between (drug), 2-within (days, blocks of trials) mixed ANOVA revealed comparable escape latencies across drug groups, with only the main effect of blocks of trials significant, $F(1,18)=16.63, p<0.001, \eta_{p}^{2}=0.480$. Thus, unsurprisingly, escape latencies improved as a function of block within a given day ( $M_{\text {latencies }}=3.66, S D=0.39$ vs. $\left.M_{\text {latencies }}=3.00, S D=0.51\right)$ but not across days of testing. All possible interactions were nonsignificant.

When the number of quadrants crossed were considered, a somewhat different yet expected pattern emerged. Unlike the escape latency data, both a main effect of days, $F(1,18)=4.68, \mathrm{p}=0.004, \eta_{p}^{2}=0.206$, and blocks were found, $F(1,18)=21.44, p<0.001, \eta_{p}^{2}=0.544$. Thus, the animals improved both within blocks $\left(M_{\text {quadrants }}=4.86, S D=0.96\right.$ vs. $\left.M_{\text {quadrants }}=3.28, S D=1.10\right)$ and between days $\left(M_{\text {quadrants }}=4.40, S D=0.69\right.$ vs. $\left.M_{\text {quadrants }}=3.74, S D=1.25\right)$. However, a significant main effect of the drug was not found. Once again, this was the case for all possible interactions.

The simple place learning phase of testing included one daily probe trial. Here, the platform was removed and the time spent in the formerly correct quadrant and the number of quadrants crossed were considered. As before, the data were analyzed with 1-between (drug), 1-within (probe) mixed ANOVA. Examination of the time data revealed that the animals spent a similar amount of time in the location associated with the previous location of the escape platform with no change across probe trials. However, when the quadrants crossed data were considered, a main effect of drug group was found, $F(2,18)=10.48, p=0.001$, $\eta_{p}^{2}=0.536$. Pairwise comparisons revealed that the high KET dose rats crossed significantly fewer quadrants $(M=5.64, S D=3.30)$ than the low dose and control rats. The latter two groups were not significantly different $(M \mathrm{~s}=13.43 \&$ 11.29).

\subsubsection{Difficult Place Learning}

Task difficulty in this phase was increased by using a single 60-watt light bulb located behind the maze curtains. Thus, there was a considerable reduction in the number of allocentric cues. For this phase, all trials were normalized and the four daily trials averaged. Examination of the resulting escape latency data using a 1-Between (drug groups), 1-Within (days) ANOVA revealed the following. The main effect of the drug group and the group $\mathrm{X}$ days interaction were both nonsignificant. Animal performance improved across days of testing, $F(4,72)=$ 
8.10, $p<0.001, \eta_{p}^{2}=310$. However, post hoc examination of the escape latencies support the observation that performance remained stable, with higher escape latencies observed on days $2\left(M_{\text {latency }}=4.32, S D=0.43\right)$ and $5\left(M_{\text {latency }}=\right.$ $4.01, S D=0.52$ ) of testing (vs. $M_{\text {latencies }}=3.10,3.24$, \& 3.53, on days $1,3, \& 4$ ).

A similar pattern-with one notable exception-was found in an examination of the accuracy data. Once again, the 1-Between (drug groups), 1-Within (days) ANOVA yielded only a main effect of day of testing, $F(4,72)=8.45, p<0.001$, $\eta_{p}^{2}=329$. However, swim accuracy improved across the days of testing with the performance on day $5\left(M_{\text {accuracy score }}=0.634, S D=0.11\right)$ superior relative to that of performance on days $1\left(M_{\text {accuracy score }}=0.494, S D=0.09\right)$ and $2\left(M_{\text {accuracy score }}=\right.$ $0.379, S D=0.10)$. Last, consideration of the probe data revealed no significant effects.

\subsubsection{Spatial Learning Set Acquisition Testing}

Examination of the spatial learning set data involved a comparison of trial one versus two performance for the first day of testing with the data from days two through five collapsed across the remaining four days assessment period. Analysis of the resulting data using a 1-between (drug), 2-within (days, trials) ANOVA produced the following findings. The main effect of drug group and day as well as the group $\mathrm{X}$ days and group $\mathrm{X}$ trials interactions were nonsignificant. On the other hand, a main effect of trials (i.e., trial 1 versus trial two escape latencies was found, $F(1,18)=32.85, p<0.001, \eta_{p}^{2}=0.646$, reflecting a difference between trial 1 versus trial 2 escape latencies across the assessment period. Of greater importance, a group $\mathrm{X}$ days $\mathrm{X}$ trial interaction was found, $F(2,18)=4.81$, $p=0.021, \eta_{p}^{2}=0.348$. The pertinent results are presented in Figure 3.

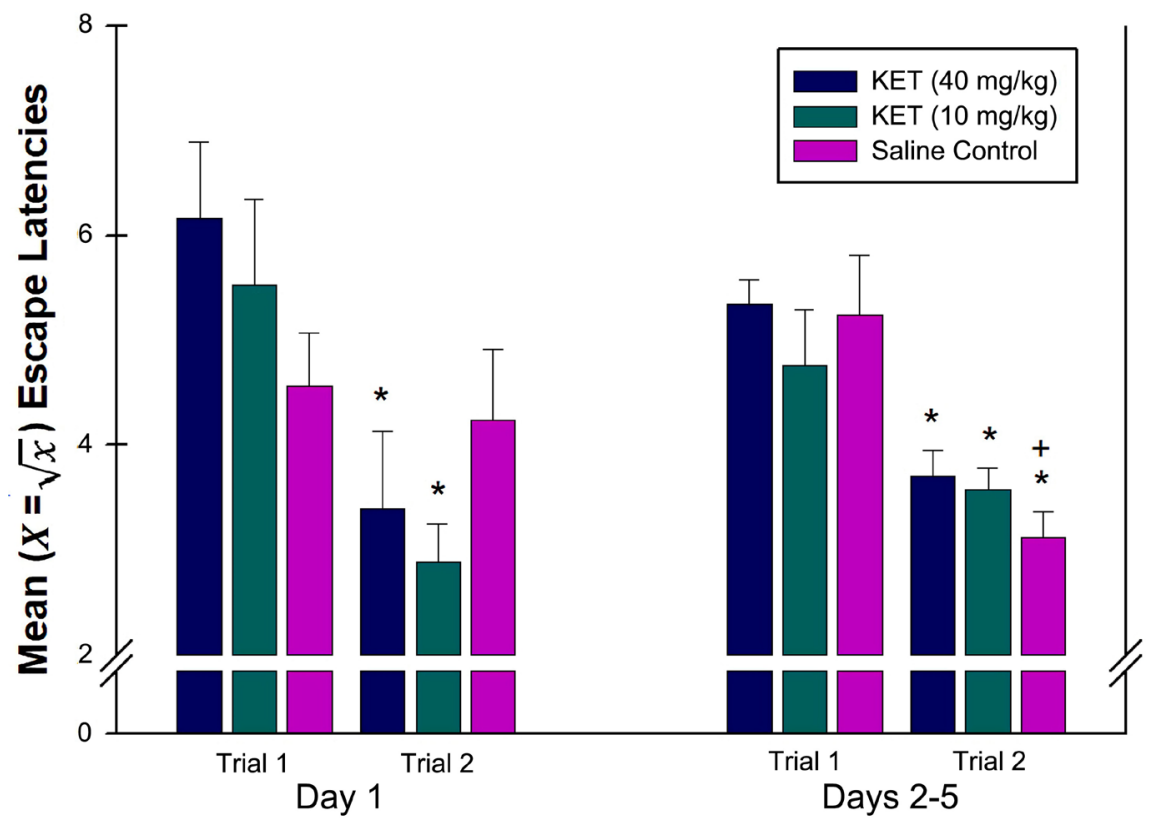

Figure 3. Mean escape latencies on trial 1 vs. trial 2 of day one and trial 1 vs. trial 2 for the data collapsed across days through 5 . ${ }^{\star}$ Significantly different from trial $1, p<0.05$. ${ }^{+}$Significantly different from KET (40 mg/kg rats). 
Paired sample decomposition of the interaction revealed the following results of interest. On day one of testing, both drug groups had significantly shorter escape latencies on trial 2 than trial 1 a trend that continued for the collapsed data from days 2 through 5. This was not the case for the control animals. However, the control animals quickly adapted, with lower response latencies on trial 2 on the collapsed days 2 through 5 data. This result was consistent with the observation that escape latencies among the high dose KET was higher than control animals on trial 2 of days two through four of testing. Once again, consideration of the accuracy data revealed only a significant main effect of trial, $F(1,18)=$ 39.11, $p<0.001, \eta_{p}^{2}=0.697$. Thus, although the escape latency performance of the control animals was disrupted in early testing, this nonetheless, did not translate to group differences in accuracy.

\subsection{Water Radial Arm Maze Assessment}

Plus Maze Response Learning

The final phase the assessment involved consideration of (nonspatial) response learning performance using a plus maze version of the standard MWM. Each day of training consisted of ten trials and continued five days per week for a total of 100 trials. Using the operational framework elucidated elsewhere [46], the total errors were subdivided into working and reference errors. Reference memory errors were scored whenever an animal initially entered one of three incorrect alleys while working memory errors were operationally defined as a re-entry into an incorrect alley not containing the escape platform.

Within the present framework, working memory errors can be suggestive of perseverative behavior, leading to longer escape latencies and impaired performance. Escape latencies were analyzed using a 1-between (drug group), 1 within (days) ANOVA. In addition to an examination of escape latencies, additional dependent measures included the number reversals (if any), the number of trials to reach the criterion for a reversal (i.e., 9 out of 10 error-free trials), working memory errors, and reference memory errors. The data were initially analyzed using a one-way between-subjects multivariate analysis of variance MANOVA, with subsequent univariate $F$ Tests if necessary.

The resulting MANOVA for the effect of the drug group was nonsignificant, Wilk's $\lambda=0.558$, approximate $F(8,30)=2.37, p=0.041, \eta_{p}^{2}=0.388$. Follow-up univariate analyses revealed that the trials to criterion differed among the three groups $F(2,18)=3.78, p=0.043, \eta_{p}^{2}=0.296$, with the high dose $\operatorname{KET~}(M=$ 21.43, $S D=3.78)$ animals reaching criterion significantly fast than control $(M=$ $34.29, S D=13.97$ ) animals. The trials to criterion among the low dose KET animals were intermediate between that of the other two groups. Perhaps more importantly, a drug effect was found for the working memory measure, $F(2,18)$ $=4.84, p=0.021, \eta_{p}^{2}=0.350$. Here, the high dose KET animals $(M=21.43, S D$ $=2.90)$ made significantly more working memory errors than either the low dose $\operatorname{KET}(M=10.86, S D=2.88)$ or control $(M=10.00, S D=3.04)$ rats. When escape latencies were explored, only a main effect of days was found, $F(9,162)=$ 
9.16, $p<0.001, \eta_{p}^{2}=0.915$. Thus, in considering escape time, the rats improved but the groups did not across the assessment period.

\section{Discussion}

In the present study, various methods were used to determine if ketamine exposure during a period that generally encompassed early adolescence had any effect on spatial and nonspatial learning and memory in adulthood. For most of the cued place learning trials, both the drug groups and the control group improved significantly over time. Similarly, these groups had improved performance over time for both the simple and difficult place learning with no significant differences among the three groups on the rate of improved performance. The rats' ability to improve their performance across trials suggests that the ketamine administration had no persisting effect on the rats' spatial learning ability, at least in regard to these tasks. The improvement rate between the two ketamine groups and the control group were similar, further suggesting spatial learning was not compromised by ketamine exposure.

When considered from the standpoint of brain development, the period of adolescence is marked by a number of both structural and functional changes in synaptic plasticity [33] [47]. Such changes lead to a variety of changes, both cortical and subcortical, with modifications observed in both gray and white matter density [48] [49]. Further, alterations in key neurotransmitter systems lead to considerable refinement of specific areas of the brain as well as neural circuits [50]. Maturation patterns are not uniform, with limbic system structures developing faster than cortical regions. In fact, the prefrontal cortex, a region responsible for a number of higher-order executive functions [51] is the final brain region to reach developmental maturity.

Considered across mammalian species, adolescent brain development is marked by a series of alterations that differ in both terms of the timing of change as well as overall functional differences [31] [47] [52]. Specifically, structures within the brain differ markedly in terms of both growth rate and timing. During brain development, greater connectivity and specialization are seen. Among the changes is the relationship between areas of the brain associated with arousal and reward and the frontal cortices and associated areas related to executive function, with concomitant changes in cognition and behavior [52]. Finally, the plasticity associated with adolescent developmental changes is required for learning and judgment in adulthood. Thus, given the physical immaturity of the adolescent brain, it is not surprising that it is highly vulnerable to the effects of drugs of abuse [53]. As a consequence, adolescent exposure to a variety of compounds can trigger dysfunction in critical maturating brain regions, that are associated with a variety of long-term debilitations in cognitive and behavioral responses [54]. However, developmental plasticity exposes the organism to greater vulnerabilities from disease or from compounds including drugs [47] [52].

Glutamate, usually considered the most important neurotransmitter with ex- 
citatory effects [52], via the NMDA receptor is a central component of fine-tuning of neural circuitry during development [55] [56] [57]. Although ketamine may have other effects [58], most of the interest in ketamine has been as a NMDA receptor antagonist [11]. NMDA receptor sites increase throughout prepubescence, peak during adolescent development, and is followed by a decrease in adulthood [59] [60] [61] [62]. However, at least where ketamine is concerned, the timing of adolescent exposure appears to be a critical variable. In the present study, ketamine exposure did not appear to adversely impact performance in rats tested in early adulthood. This finding is at odds with another investigation in our laboratory, where ketamine exposure later in adolescence/early adulthood had an adverse impact on the performance of drug-free rats subsequently tested in adulthood [38]. Conversely, the present results are consistent with those of Bates and Trujillo [63] who reported finding no cognitive deficits per se-although evidence of a mild spatial learning deficit-following adolescent exposure. In the present study, the drug washout period was considerably longer than the 20-day abstinence period used by Bates and Trujillo. Nonetheless, future research is necessary to more clearly delineate the effects of ketamine and the associated neurodevelopmental boundaries associated with differing effects.

Here, as elsewhere, the timing of exposure appears critical [47] [64]-[69]. For example, nicotine or alcohol exposure as well as exposure to stressors during early adolescence produces effects that are more profound when social/affective measures or drug self-administration behaviors are considered [47]. On the other hand, alterations in cognitive performance are more likely following drug exposure later in adolescence when the critical structures that drive successful performance are undergoing maturation during the exposure period [47]. While speculative, one possibility for the different time of exposure effects may lie in consideration of the molecular signature [70] of relevant signaling pathways [47]. As Spear noted, when the phenomenon of long-term potentiation is considered, there is evidence of a developmental difference in the role of the enzyme protein kinase A (PKA), where PKA is required for hippocampal LTP in late adolescent/early adult rats but not in rats in early/mid-adolescence [71]. Thus, differences in the timing of exposure during development could impact later measurements of behavior in adulthood. Specifically, late adolescent exposure of ketamine may have an impact on slowly developing systems such as the prefrontal cortices, with effects seen in tasks that assess cognitive processes associated with these systems.

Spatial and non-spatial memory appear to be dependent on different brain substrates, with considerable support seen in studies demonstrating brain lesions of a given area disrupting one type of memory, but sparing the other [72]. However, currently these is no consensus on the specific areas of the brain and concomitant networks that are associated with improvement in specific cognitive capabilities during adolescent development [73]. At least from a neuropsychological standpoint, correlations with specific regional activation patterns will be 
impacted by such variables as the type of test and its difficulty, environmental factors, and a variety of methodological considerations [73].

Given the present results as well as others described earlier, our knowledge of the potential for ketamine to produce persisting alterations in behavior and cognition following adolescent exposure remains incomplete. Indeed, the effects of ketamine are complex, with interactions among multiple neurotransmitter systems [63], including those cholinergic, aminergic, and opioid-ergic in nature [74]. Further, a variety of non-NMDA mediated effects on glutamate receptors have been reported [75] [76]. In addition, an issue in need of resolution is the question as to whether adolescent ketamine exposure contributes to persisting alterations in brain development subsequently compromising adult behavior. In this regard, a nonhuman primate model may produce additional insight. At any rate, individuals during late adolescence are susceptible to both substance abuse as well as mental illness [39]. This should be taken into consideration if ketamine becomes a treatment option for mental illnesses. Using ketamine therapeutically may put these individuals at a greater risk for long-term impairments caused by repeated doses of ketamine.

\section{Acknowledgements}

The authors would like to thank the School of Arts \& Sciences for their support.

\section{Funding}

This research was supported by a Quality Initiative Grant awarded to David M. Compton.

\section{Conflicts of Interest}

The authors declare no conflicts of interest regarding the publication of this paper.

\section{References}

[1] Dotson, J.W., Ackerman, D.L. and West, L.J. (1995) Ketamine Abuse. Journal of Drug Issues, 25, 751-757. https://doi.org/10.1177/002204269502500407

[2] Domino, E.F., Domino, S.E., Smith, R.E., Domino, L.E., Goulet, J.R., Domino, K.E. and Zsigmond, E.K. (1984) Ketamine Kinetics in Unpremedicated and Diazepam-Premedicated Subjects. Clinical Pharmacology \& Therapeutics, 36, 645-553. https://doi.org/10.1038/clpt.1984.235

[3] Moghaddam, B., Adams, B., Verma, A. and Daly, D. (1997) Activation of Glutamatergic Neurotransmission by Ketamine: A Novel Step in the Pathway from NMDA Receptor Blockade to Dopaminergic and Cognitive Disruptions Associated with the Prefrontal Cortex. Journal of Neuroscience, 17, 2921-2927. https://doi.org/10.1523/JNEUROSCI.17-08-02921.1997

[4] Dahan, A., Olofsen, E., Sigtermans, M., Noppers, I., Niesters, M., Aarts, L., Bauer, M. and Sarton, E. (2011) Population Pharmacokinetic-Pharmacodynamic Modeling of Ketamine-Induced Pain Relief of Chronic Pain. European Journal of Pain, 15, 258-267. https://doi.org/10.1016/j.ejpain.2010.06.016 
[5] Mion, G. (2017) History of Anaesthesia: The Ketamine Story-Past, Present and Future. European Journal of Anaesthesiology, 34, 571-575. https://doi.org/10.1097/EJA.0000000000000638

[6] Nejati, A., Jalili, M., Abbasi, S., Sarwari, F.T., Bidari, A., Ghajarzadeh, M. and Akhgar, A. (2019) Intranasal Ketamine Reduces Pain of Digital Nerve Block: A Double Blind Randomized Clinical Trial. American Journal of Emergency Medicine, 37, 1622-1626. https://doi.org/10.1016/j.ajem.2018.11.026

[7] Nejati, A., Moharari, R.S., Ashraf, H., Labaf, A. and Golshani, K. (2011) Ketamine/Propofol versus Midazolam/Fentanyl for Procedural Sedation and Analgesia in the Emergency Department: A Randomized, Prospective, Double-Blind Trial. Academic Emergency Medicine, 18, 800-806.

https://doi.org/10.1111/j.1553-2712.2011.01133.x

[8] Ralph, Q., Paolino, C. and Meara, D. (2019) Subjective Changes in Mood and Chronic Pain Status-Post Intravenous Ketamine for Oral and Facial Surgery. Oral Surgery, Oral Medicine, Oral Pathology and Oral Radiology, 128, e22. https://doi.org/10.1016/j.oooo.2019.02.250

[9] Daly, E.J., Singh, J.B., Fedgchin, M., Cooper, K., Lim, P., Shelton, R.C., Thase, M.E., Winokur, A., Van Nueten, L., Manji, H. and Drevets, W.C. (2018) Efficacy and Safety of Intranasal Esketamine Adjunctive to Oral Antidepressant Therapy in Treatment-Resistant Depression a Randomized Clinical Trial. JAMA Psychiatry, 75, 139-148. https://doi.org/10.1001/jamapsychiatry.2017.3739

[10] Ramachandran, V.S. and Seckel, E.L. (2010) Using Mirror Visual Feedback and Virtual Reality to Treat Fibromyalgia. Medical Hypotheses, 75, 495-496. https://doi.org/10.1016/j.mehy.2010.07.003

[11] Zorumski, C.F., Izumi, Y. and Mennerick, S. (2016) Ketamine: NMDA Receptors and Beyond. Journal of Neuroscience, 36, 11158-11164.

https://doi.org/10.1523/JNEUROSCI.1547-16.2016

[12] McDougall, S.A., Moran, A.E., Baum, T.J., Apodaca, M.G. and Real, V. (2017) Effects of Ketamine on the Unconditioned and Conditioned Locomotor Activity of Preadolescent and Adolescent Rats: Impact of Age, Sex, and Drug Dose. Psychopharmacology, 234, 2683-2696. https://doi.org/10.1007/s00213-017-4660-3

[13] Aalto, S., Ihalainen, J., Hirvonen, J., Kajander, J., Scheinin, H., Tanila, H., Någren, K., Vilkman, H., Gustafsson, L.L., Syvälahti, E. and Hietala, J. (2005) Cortical Glutamate-Dopamine Interaction and Ketamine-Induced Psychotic Symptoms in Man. Psychopharmacology, 182, 375-383. https://doi.org/10.1007/s00213-005-0092-6

[14] Amann, L.C., Halene, T.B., Ehrlichman, R.S., Luminais, S.N., Ma, N., Abel, T. and Siegel, S.J. (2009) Chronic Ketamine Impairs Fear Conditioning and Produces Long-Lasting Reductions in Auditory Evoked Potentials. Neurobiology of Disease, 35, 311-317. https://doi.org/10.1016/j.nbd.2009.05.012

[15] Dimaggio, C., Sun, L.S. and Li, G. (2011) Early Childhood Exposure to Anesthesia and Risk of Developmental and Behavioral Disorders in a Sibling Birth Cohort. Anesthesia \& Analgesia, 113, 1143-1151. https://doi.org/10.1213/ANE.0b013e3182147f42

[16] Miech, R.A., Johnston, L.D., O’Malley, P.M., Bachman, J.G., Schulenberg, J.E. and Patrick, M.E. (2020) Monitoring the Future National Survey Results on Drug Use, 1975-2019: Volume I, Secondary School Students. Institute for Social Research, The University of Michigan, Ann Arbor. https://doi.org/10.3998/2027.42/150622 http://monitoringthefuture.org/pubs.html\#monographs

[17] Tan, S., Lam, W.P., Wai, M.S., Yu, W.H. and Yew, D.T. (2012) Chronic Ketamine 
Administration Modulates Midbrain Dopamine System in Mice. PLoS ONE, 7, e43947. https://doi.org/10.1371/journal.pone.0043947

[18] Palamar, J.J., Salomone, A., Rutherford, C. and Keyes, K.M. (2020) Extensive Underreported Exposure to Ketamine among Electronic Dance Music Party Attendees. Journal of General Internal Medicine. https://doi.org/10.1007/s11606-020-05672-x

[19] Palamar, J.J., Acosta, P., Le, A., Cleland, C.M. and Nelson, L.S. (2019) Adverse Drug-Related Effects among Electronic Dance Music Party Attendees. International Journal of Drug Policy, 73, 81-87. https://doi.org/10.1016/j.drugpo.2019.07.005

[20] Palamar, J.J., Griffin-Tomas, M. and Ompad, D.C. (2015) Illicit Drug Use among Rave Attendees in a Nationally Representative Sample of Us High School Seniors. Drug and Alcohol Dependence, 152, 24-31. https://doi.org/10.1016/j.drugalcdep.2015.05.002

[21] Lofwall, M.R., Griffiths, R.R. and Mitzer, M.Z. (2006) Cognitive and Subjective Acute Dose Effects of Intramuscular Ketamine in Healthy Adults. Experimental and Clinical Psychopharmacology, 14, 439-449. https://doi.org/10.1037/1064-1297.14.4.439

[22] Morgan, C.J.A., Riccelli, M., Maitland, C.H. and Curran, H.V. (2004) Long-Term Effects of Ketamine: Evidence for a Persisting Impairment of Source Memory in Recreational Users. Drug and Alcohol Dependence, 75, 301-308. https://doi.org/10.1016/j.drugalcdep.2004.03.006

[23] Morgan, C.J.A., Mofeez, A., Brandner, B., Bromley, L. and Curran, H.V. (2004) Acute Effects of Ketamine on Memory Systems and Psychotic Symptoms in Healthy Volunteers. Neuropsychopharmacology, 29, 208-218. https://doi.org/10.1038/sj.npp.1300342

[24] Dillon, P., Copeland, J. and Jansen, K. (2003) Patterns of Use and Harms Associated with Non-Medical Ketamine Use. Drug and Alcohol Dependence, 69, 23-28. https://doi.org/10.1016/S0376-8716(02)00243-0

[25] Curran, H.V. and Morgan, C. (2000) Cognitive, Dissociative and Psychotogenic Effects of Ketamine in Recreational Users on the Night of Drug Use and 3 Days Later. Addiction, 95, 575-590. https://doi.org/10.1046/j.1360-0443.2000.9545759.x

[26] Driesen, N.R., McCarthy, G., Bhagwagar, Z., Bloch, M.H., Calhoun, V.D., D’souza, D.C., Gueorguieva, R., He, G., Leung, H.-C., Ramani, R., Anticevic, A., Suckow, R.F., Morgan, P.T. and Krystal, J.H. (2013) The Impact of NMDA Receptor Blockade on Human Working Memory-Related Prefrontal Function and Connectivity. Neuropsychopharmacology, 38, 2613. https://doi.org/10.1038/npp.2013.170

[27] Morgan, C.J., Muetzelfeldt, L. and Curran, H.V. (2009) Ketamine Use, Cognition and Psychological Wellbeing: A Comparison of Frequent, Infrequent and Ex-Users with Polydrug and Non-Using Controls. Addiction, 104, 77-87. https://doi.org/10.1111/j.1360-0443.2008.02394.x

[28] Morgan, C.J., Muetzelfeldt, L. and Curran, H.V. (2010) Consequences of Chronic Ketamine Self-Administration upon Neurocognitive Function and Psychological Wellbeing: A 1-Year Longitudinal Study. Addiction, 105, 121-133. https://doi.org/10.1111/j.1360-0443.2009.02761.x

[29] Sassano-Higgins, S., Baron, D., Juarez, G., Esmaili, N. and Gold, M. (2016) A Review of Keta Mine Abuse and Diversion. Depression and Anxiety, 33, 718-727. https://doi.org/10.1002/da.22536

[30] Tirelli, E., Laviola, G. and Adriani, W. (2003) Ontogenesis of Behavioral Sensitization and Conditioned Place Preference Induced by Psychostimulants in Laboratory Rodents. Neuroscience and Biobehavioral Reviews, 27, 163-178. 
https://doi.org/10.1016/S0149-7634(03)00018-6

[31] Spear, L.P. (2000) The Adolescent Brain and Age-Related Behavioral Manifestations. Neuroscience and Biobehavioral Reviews, 24, 417-463.

https://doi.org/10.1016/S0149-7634(00)00014-2

[32] Salmanzadeh, H., Ahmadi-Soleimani, S.M., Pachenari, N., Azadi, M., Halliwell, R.F., Rubino, T. and Azizi, H. (2020) Adolescent Drug Exposure: A Review of Evidence for the Development of Persistent Changes in Brain Function. Brain Research Bulletin, 156, 105-117. https://doi.org/10.1016/j.brainresbull.2020.01.007

[33] Spear, L.P. (2016) Consequences of Adolescent Use of Alcohol and Other Drugs: Studies Using Rodent Models. Neuroscience and Biobehavioral Reviews, 70, 228-243. https://doi.org/10.1016/j.neubiorev.2016.07.026

[34] Andersen, S.L. (2003) Trajectories of Brain Development: Point of Vulnerability or Window of Opportunity? Neuroscience and Biobehavioral Reviews, 27, 3-18. https://doi.org/10.1016/S0149-7634(03)00005-8

[35] Schepis, T.S., Adinoff, B. and Rao, U. (2008) Neurobiological Processes in Adolescent Addictive Disorders. American Journal of Addictions, 17, 6-23.

https://doi.org/10.1080/10550490701756146

[36] Lisdahl, K.M., Sher, K.J., Conway, K.P., Gonzalez, R., Ewing, S.W.F., Nixon, S.J., Tapert, S., Bartsch, H., Goldstein, R.Z. and Heitzeg, M. (2018) Adolescent Brain Cognitive Development (ABCD) Study: Overview of Substance Use Assessment Methods. Developmental Cognitive Neuroscience, 32, 80-96.

https://doi.org/10.1016/j.dcn.2018.02.007

[37] Compton, D.F., Wedge, T.J. and Poulton, K. (2013) A Neuropsychological Assessment of the Effects of Chronic Ketamine Exposure in a Rodent Model of Drug Abuse. International Journal of Life Science and Medical Research, 3, 179-192. https://doi.org/10.5963/LSMR0305001

[38] Davis, J.M., Compton, D.M., Heit, M., Fravel, A. and Wood, K. (2020) Neuropsychological Assessment of Spatial and Nonspatial Learning and Memory in Rats Following Ketamine Exposure during Late Adolescence. Journal of Behavioral and Brain Research. https://doi.org/10.4236/jbbs.2020.1012036

[39] Schwinn, T.M., Schinke, S.P. and Trent, D.N. (2010) Substance Use among Late Adolescent Urban Youths: Mental Health and Gender Influences. Addictive Behaviors, 35, 30-34. https://doi.org/10.1016/j.addbeh.2009.08.005

[40] Hartman, R.E., Lee, J.M., Zipfel, G.J. and Wozniak, D.F. (2005) Characterizing Learning Deficits and Hippocampal Neuron Loss Following Transient Global Cerebral Ischemia in Rats. Brain Research, 1043, 48-56.

https://doi.org/10.1016/j.brainres.2005.02.030

[41] Compton, D.M., Luetzenberg, F.S. and Watkins, E. (2016) Tripping the Light Fantastic: Modelling the Consequences of Recreational Use of MDMA or 5-MeO-DIPT in Humans Using Weekend "Rave" Exposures in Rat. Psychology \& Neuroscience, 9, 105-124. https://doi.org/10.1037/pne0000043

[42] Fellows, B.J. (1967) Chance Stimulus Sequences for Discrimination Tasks. Psychological Bulletin, 67, 87-92. https://doi.org/10.1037/h0024098

[43] McDaniel, W.F., Via, J.D., Smith, J.S., Wells, D.L., Fu, J.J. Bishop, J.F., Ledesma, H.M., et al. (1995) Unilateral Injury of Posterior Parietal Cortex and Spatial Learning in Hooded Rats. Behavioural Brain Research, 70, 165-179. https://doi.org/10.1016/0166-4328(95)80006-9

[44] Compton, D.M., Dietrich, K.L., Selinger, M.C. and Testa, E.K. (2011) 5-MethoxyN,N-di(iso)propyl Tryptamine Hydrochloride (Foxy)-Induced Cognitive Deficits in 
Rat after Exposure in Adolescence. Physiology \& Behavior, 103, 203-209. https://doi.org/10.1016/j.physbeh.2011.01.021

[45] IBM SPSS Statistics for Windows (Version 23.0) [Computer Software]. IBM Corp., Armonk.

[46] Compton, D.M., Selinger, M.C., Westman, E. and Otero, P. (2011) Differentiation of MDMA or 5-MeO-DIPT Induced Cognitive Deficits in Rats Following Adolescent Exposure. Psychology \& Neuroscience, 4, 157-169. https://doi.org/10.3922/j.psns.2011.1.018

[47] Spear, L.P. (2015) Adolescent Alcohol Exposure: Are There Separable Vulnerable Periods within Adolescence. Physiology \& Behavior, 148, 122-130. https://doi.org/10.1016/j.physbeh.2015.01.027

[48] Gogtay, N., Giedd, J.N., Lusk, L., Hayashi, K.M., Greenstein, D., Vaituzis, A.C., Nugent III, T.F., Herman, D.H., Clasen, L.S., Toga, A.W., Rapoport, J.L. and Thompson, P.M. (2004) Dynamic Mapping of Human Cortical Development during Childhood through Early Adulthood. Proceedings of the National Academy of Sciences of the United States of America, 101, 8174-8179.

https://doi.org/10.1073/pnas.0402680101

[49] Sowell, E.R., Thompson, P.M., Tessner, K.D. and Toga, A.W. (2001) Mapping Continued Brain Growth and Gray Matter Density Reduction in Dorsal Frontal Cortex: Inverse Relationships during Postadolescent Brain Maturation. Journal of Neuroscience, 21, 8819-8829. https://doi.org/10.1523/JNEUROSCI.21-22-08819.2001

[50] Schulz, K.M. and Sisk, C.L. (2016) The Organizing Actions of Adolescent Gonadal Steroid Hormones on Brain and Behavioral Development. Neuroscience and Biobehavioral Reviews, 70, 148-158. https://doi.org/10.1016/j.neubiorev.2016.07.036

[51] Badre, D., Kayser, A.S. and D'Esposito, M. (2010) Frontal Cortex and the Discovery of Abstract Action Rules. Neuron, 66, 315-326. https://doi.org/10.1016/j.neuron.2010.03.025

[52] Dow-Edwards, D., MacMaster, F.P., Peterson, B.S., Niesink, R., Andersen, S. and Braams, B.R. (2019) Experience during Adolescence Shapes Brain Development: From Synapses and Networks to Normal and Pathological Behavior. Neurotoxicology and Teratology, 76, Article ID: 106834. https://doi.org/10.1016/j.ntt.2019.106834

[53] Winters, K.C., Fahnhorst, T., Botzet, A., Lee, S. and Lalone, B. (2012) Brief Intervention for Drug-Abusing Adolescents in a School Setting: Outcomes and Mediating Factors. Journal of Substance Abuse Treatment, 42, 279-288.

https://doi.org/10.1016/j.jsat.2011.08.005

[54] Pascual, M., Montesinos, J. and Guerri, C. (2018) Role of the Innate Immune System in the Neuropathological Consequences Induced by Adolescent Binge Drinking. Journal of Neuroscience Research, 96, 765-780. https://doi.org/10.1002/jnr.24203

[55] Citri, A. and Malenka, R.C. (2008) Synaptic Plasticity: Multiple Forms, Functions, and Mechanisms. Neuropsychopharmacology 33, 18-41.

https://doi.org/10.1038/sj.npp.1301559

[56] Colonnese, M.T. and Constantine-Paton, M. (2006) Developmental Period for N-methyl-D-aspartate (NMDA) Receptor-Dependent Synapse Elimination Correlated with Visuotopic Map Refinement. Journal of Comparative Neurology, 494, 738-751. https://doi.org/10.1002/cne.20841

[57] Hofer, M. and Constantine-Paton, M. (1994) Regulation of N-methyl-D-aspartate (NMDA) Receptor Function during the Rearrangement of Developing Neuronal 
Connections. Progress in Brain Research, 102, 277-285.

https://doi.org/10.1016/S0079-6123(08)60546-4

[58] Tyler, M.W., Yourish, H.B., Ionescu, D.F. and Haggarty, S.J. (2017) Classics in Chemical Neuroscience: Ketamine. ACS Chemical Neuroscience, 8, 1122-1134. https://doi.org/10.1021/acschemneuro.7b00074

[59] Colwell, C.S., Cepeda, C., Crawford, C. and Levine, M.S. (1998) Postnatal Development of Glutamate Receptor-Mediated Responses in the Neostriatum. Developmental Neuroscience, 20, 154-163. https://doi.org/10.1159/000017310

[60] Henson, M.A., Roberts, A.C., Salimi, K., Vadlamudi, S., Hamer, R.M., Gilmore, J.H., Jarskog, F. and Philpot, B.D. (2008) Developmental Regulation of the NMDA Receptor Subunits, NR3A and NR1, in Human Prefrontal Cortex. Cerebral Cortex, 18, 2560-2573. https://doi.org/10.1093/cercor/bhn017

[61] Insel, T.R., Miller, L.P. and Gelhard, R.E. (1990) The Ontogeny of Excitatory Amino Acid Receptors in Rat Forebrain-I. N-methyl-D-aspartate and Quisqualate Receptors. Neuroscience, 35, 31-43. https://doi.org/10.1016/0306-4522(90)90117-M

[62] Luo, J., Bosy, T.Z., Wang, Y., Yasuda, R.P. and Wolfe, B.B. (1996) Ontogeny of NMDA R1 Subunit Protein Expression in Five Regions of Rat Brain. Developmental Brain Research, 92, 10-17. https://doi.org/10.1016/0165-3806(95)00191-3

[63] Bates, M.L.S. and Trujillo, K.A. (2019) Long-Lasting Effects of Repeated Ketamine Administration in Adult and Adolescent Rats. Behavioural Brain Research, 369, Article ID: 111928. https://doi.org/10.1016/j.bbr.2019.111928

[64] Adriani, W., Granstrem, O., Macri, S., Izykeonva, G., Dambinova, S. and Laviola, G. (2004) Behavioral and Neurochemical Vulnerability during Adolescence in Mice: Studies with Nicotine. Neuropsychopharmacology, 29, 869-878.

https://doi.org/10.1038/sj.npp.1300366

[65] Adriani, W., Macri, S., Pacifici, R. and Laviola, G. (2002) Peculiar Vulnerability to Nicotine Oral Self-Administration in Mice during Early Adolescence. Neuropsychopharmacology, 27, 212-224. https://doi.org/10.1016/S0893-133X(02)00295-6

[66] Dao, J.M., McQuown, S.C., Loughlin, S.E., Belluzzi, J.D. and Leslie, F.M. (2011) Nicotine Alters Limbic Function in Adolescent Rat by a 5-HT1A Receptor Mechanism. Neuropharmacology, 36, 1319-1331. https://doi.org/10.1038/npp.2011.8

[67] Einon, D.F. and Morgan, M.J. (1977) A Critical Period for Social Isolation in the Rat. Developmental Psychobiology, 10, 123-132.

https://doi.org/10.1002/dev.420100205

[68] Onaolapo, A.Y., Ayeni, O.J., Ogundeji, M.O., Ajao, A., Onaolapo, O.J. and Owolabi, A.R. (2019) Subchronic Ketamine Alters Behaviour, Metabolic Indices and Brain Morphology in Adolescent Rats: Involvement of Oxidative Stress, Glutamate Toxicity and Caspase-3-Mediated Apoptosis. Journal of Chemical Neuroanatomy, 96, 22-33. https://doi.org/10.1016/j.jchemneu.2018.12.002

[69] Varlinskaya, E.I., Truxell, E.M. and Spear, L.P. (2014) Chronic Intermittent Ethanol during Adolescence: Effects on Social Behavior and Ethanol Sensitivity in Adulthood. Alcohol, 48, 433-444. https://doi.org/10.1016/j.alcohol.2014.01.012

[70] Sung, J., Wang, Y., Chandrasekaran, S., Witten, D.M. and Price, N.D. (2012) Molecular Signatures from Omics Data: From Chaos to Consensus. Biotechnology Journal, 7, 946-957. https://doi.org/10.1002/biot.201100305

[71] Lu, Y., Allen, M., Halt, A.R., Weisenhaus, M., Dallapiazza, R.F., Hall, D.D., et al. (2007) Age-Dependent Requirement of AKAP150-Anchored PKA and GluR2-Lacking AMPA Receptors in LTP. EMBO Journal, 26, 4879-4890.

https://doi.org/10.1038/sj.emboj.7601884 
[72] Rudy, J.W. (2014) The Neurobiology of Learning and Memory, 2nd Edition, Sinauer (US), Sunderland.

[73] Spear, L.P. (2011) Brain Development. In: Brown, B.B. and Prinstein, M.J., Eds., Encyclopedia of Adolescence, Academic Press, London, 87-95.

https://doi.org/10.1016/B978-0-12-373951-3.00006-5

[74] Sleigh, J., Harvey, M., Voss, L. and Denny, B. (2014) Ketamine-More Mechanisms of Action than Just NMDA Blockade. Trends in Anaesthesia and Critical Care, 4, 76-81. https://doi.org/10.1016/j.tacc.2014.03.002

[75] Cai, Y.C., Ma, L., Fan, G.H., Zhao, J., Jiang, L.Z. and Pei, G. (1997) Activation of N-methyl-D-aspartate Receptor Attenuates Acute Responsiveness of Delta-Opioid Receptors. Molecular Pharmacology, 51, 583-587.

https://doi.org/10.1124/mol.51.4.583

[76] Wang, M., Wong, A.H. and Liu, F. (2012) Interactions between NMDA and Dopamine Receptors: A Potential Therapeutic Target. Brain Research, 1476, 154-163. https://doi.org/10.1016/j.brainres.2012.03.029 